\title{
Short Communication: Seed Viability Test and Pathogenecity Assessment of Most Prevalent Fungi Infecting Sesamum indicum L.
}

\author{
Brian Gagosh Nayyar ${ }^{1}$, Abida Akram ${ }^{1}$, Shaista Akhund ${ }^{1}$ and Maria Rafiq ${ }^{2}$ \\ ${ }^{I}$ Department of Botany, Pir Mehr Ali Shah Arid Agriculture University, Rawalpindi 46300, Pakistan \\ ${ }^{2}$ Department of Botany, Institute of Pure and Applied Biology, Bahauddin Zakariya University, Multan 60000,
} Pakistan

\begin{abstract}
Sesame is an important source of oil and protein. The quality of sesame crop is adversely affected by various fungal diseases, which not only reduce its production but also affects its export in various countries. During the mycological analysis of sesame seeds in our previous report, a total number of 36 species belonging to 10 genera of fungi were isolated. The prevalent genera were Alternaria, Aspergillus, Cercospora, Fusarium, Penicillium and Rhizopus. The present study aimed to test the seed viability and pathogenecity of the predominant fungi infecting sesame in region of Sialkot, Pakistan. Results indicated that the germination rate was increased and seed borne fungi were eliminated with seed sterilization. The pathogenecity of isolates was evaluated at seedling stage which confirmed the incidence of prevalent fungi. Plant growth was significantly decreased in inoculated plants as compared to un-inoculated plants. Deleterious effects on roots were observed which ultimately affected the whole seedlings. Therefore, we may conclude that fungal test species used in this study are virulent pathogens of sesame which can be controlled by different seed treatments before sowing.
\end{abstract}

Key Words: Pathogenecity; Sesame; Seed borne; Seed Viability.

\section{Introduction}

Sesame (Sesamum indicum L.) is one of the important oil seed crops of Pakistan. The seed of sesame contains 20 to 30\% protein (Khidir, 1997) and about 50\% oil of high quality (Roy et al., 2009). The importance of sesame lies in the quality of the oil, the presence of antioxidants sesamin and sesmolin, its antiquity and use in religious rituals in India, Egypt and the Persian region. The world production is estimated at 3.66 million tons, with Asia and Africa producing 2.55 and 0.95 million tons respectively (Anonymous, 2008). China, India, and Myanmar are the leading producers of sesame, followed by Sudan, Nigeria, Pakistan, Bangladesh, Ethiopia, Thailand, Turkey, and Mexico (FAO, 2004).

After harvesting seeds are stored in different storage conditions and if these storage conditions are not proper various microbes like viruses, bacteria, fungi and nematode interact with these seeds. Among these microbes, fungi play a dominant role in decreasing quality and longetivity of the seeds. Fungi cause various abnormalities to the seeds like discolored seeds, damaged seeds, shrunken seeds, undersized, rotted seeds and reduced in germinability. Fungal organisms play significant role in infection, altering quality and longevity of seeds during the storage (Christensen and Kaufman, 1969).

The area and production of this crop is declining in the traditional areas due to severe biotic stresses, such as bacterial blight (Xanthomonas campestris pv. sesami), phyllody (Mycoplasma-like organism), Fusarium wilt (Fusarium oxysporum), powdery mildew (Oidium erysiphoides), Alternaria leaf spot (Alternaria sesami) and Cercospora leaf spot (Cercospora sesami) (Daniel, 2008). In our previous study, predominant genera of fungi associated with sesame seeds were Alternaria, Aspergillus, Fusarium, Cercospora, Penicillium and Rhizopus (Nayyar et al., 2013). Therefore, the objective of this study was the determination of seed viability and pathogenecity of fungal isolates obtained from sesame seeds in our previous study.

Test Species

\section{Materials And Methods}

Seven prevalent fungal species viz. Alternaria alternata, Aspergillus flavus, Aspergillus niger, Cercospora sp., Fusarium oxysporum, Penicillium egyptiacum and Rhizopus oryzae associated with sesame seeds were selected for this study.

\section{Seed Viability}

Germination test was carried out in plastic pots. Hundred seeds treated with $2 \% \mathrm{NaOCl}$ along with nontreated seeds of sesame were randomly selected and sown in plastic pots $(12 \mathrm{~cm}$ diameter) containing sterilized soil (soil, sand and farmyard manure at the ratio 1:1:1) and incubated in growth chamber at $25^{\circ} \mathrm{C}$ for 7 days. At the end of incubation period, the number of ungerminated and germinated seeds were counted. The emerged 
seedlings were graded as normal, abnormal and infected (Altaf et al., 2004). The percentage was recorded by following formula;

$$
\text { Percent germination }=\underline{\text { No. of seed germinated }} \times 100
$$

Total seeds

\section{Pathogenic Effect of Isolated Fungi on Germination}

Pathogenic effect of isolated fungi on seedlings was also studied in plastic pots of $12 \mathrm{~cm}$ diameter. Test species were multiplied on Potato Dextrose Agar. The inoculums were prepared by mixing $1 \mathrm{gm}$ culture in $20 \mathrm{ml}$ autoclaved distilled water. Then the conidial suspension of individual fungus was mixed with sterilized soil (soil, sand and farmyard manure at the ratio 1:1:1) in pots. Twenty five seeds per pot were planted in three replicates. Control was free of fungal suspension. Effect of each pathogenic fungus was recorded (Afzal et al., 2010).

\section{Seed Viability}

\section{Result And Discussion}

Mycoflora associated with seeds affected the seed health and resulted in reduced seed germination, and seedling abnormality. In present study, sesame seeds were assessed in pots to know the effect of seed borne fungi on germination seedling health. It was observed that the germination rate was increased and seed borne fungi were eliminated with sterilization. Surface sterilized seeds gave 80 percent normal seedlings, 14 percent abnormal seedlings and 6 percent ungerminated seed. A. flavus, A. niger and F. oxysporum were isolated from abnormal seedlings and showed greater germination. Naturally infected seeds gave 64 percent normal seedlings, 26 percent abnormal and 10 percent ungerminated seeds. Fungi such as A. alternata, A. flavus, A. niger, $F$. oxysporum and P. egyptiacum were isolated from abnormal seedlings (Table 1). Altaf et al., (2004) found the presence of A. niger and A. flavus from naturally infected sesame seeds showing similarity with present work and observed 11-43 percent abnormal seedlings and 8-35 percent reduction in seed germination. So the results suggested that increase of seed infection by seed borne fungi reduce seed germination.

Table 1: Effect of Mycoflora on Seed Germination

\begin{tabular}{|c|c|c|c|l|}
\hline Treatments & $\begin{array}{c}\text { Normal seedlings } \\
\text { \%age }\end{array}$ & $\begin{array}{c}\text { Abnormal seedlings } \\
\text { \%age }\end{array}$ & $\begin{array}{c}\text { Un germinated seeds } \\
\text { \%age }\end{array}$ & \multicolumn{1}{c|}{ Fungi isolated } \\
\hline Surface sterilized seeds & 80 & 14 & 6 & $\begin{array}{l}\text { Aspergillus flavus } \\
\text { Aspergillus niger } \\
\text { Fusarium oxysporum }\end{array}$ \\
\hline Naturally infected seeds & 64 & 26 & 10 & $\begin{array}{l}\text { Alternaria alternata } \\
\text { Aspergillus flavus } \\
\text { Aspergillus niger } \\
\text { Fusarium oxysporum } \\
\text { Penicillium egyptiacum }\end{array}$ \\
\hline
\end{tabular}

\section{Pathogenic Effect of Isolated Fungi on Sesame Seeds}

In this study, seven fungi viz. A. alternata, A. flavus, A. niger, Cercospora sp., F. oxysporum, $P$. egyptiacum and $R$. oryzae isolated from sesame seeds were evaluated for their pathogenic effect on germination and data is presented in Table $2 \&$ Figure 1 . Infected root and stem, reduced growth, and weak stem were observed in seedlings infected with A. alternata. Healthy plants were about 55 percent. A. flavus caused reduced growth and healthy plants were about 70 percent. In seeds treated with A. niger, infected roots, weak stem and reduced growth were observed and healthy plants were about 13 percent. In $R$. oryzae, reduced growth, infected roots \& stem, weak stem was observed and healthy plants were 30 percent, $P$. egyptiacum caused infection of root, weak stem and healthy plants were 26 percent. Cercospora sp. caused infection on stem, weak stem, reduced growth 40 percent healthy plants. Whereas, $F$. oxysporum produced short, infected leaves and caused reduction in growth. The percentage of healthy plants was 32. The result is similar with study of Mahdy et al., 2007. He observed that sesame seeds inoculated with $F$. oxysporum gave 16.4 to 43.4 percent healthy plants while 16.8 percent plants were wilted.

Table 2: Pathogenic effect of isolated fungi on sesame seedlings

\begin{tabular}{|c|l|l|c|}
\hline S. No. & Fungi isolated & \multicolumn{1}{|c|}{ Pathogenic Effect } & Healthy Plants \\
\hline 1 & A. alternata & Infected root \& stem, Weak stem, Reduced growth & $55 \%$ \\
\hline 2 & A. flavus & Reduced growth & $70 \%$ \\
\hline 3 & A. niger & Reduced growth, Infected roots, Weak stem & $13 \%$ \\
\hline 4 & Cercospora sp. & Infected stem, Weak stem, Reduced growth & $40 \%$ \\
\hline 5 & P. egyptiacum & Infected root, Weak stem & $26 \%$ \\
\hline 6 & R. oryzae & Reduced growth, Infected roots \& stem, Weak stem & $30 \%$ \\
\hline 7 & F. oxysporum & Reduced growth, Leaves short \& infected & $32 \%$ \\
\hline
\end{tabular}


Figure 1: Pathogenic effect of isolated fungi on sesame seedlings health

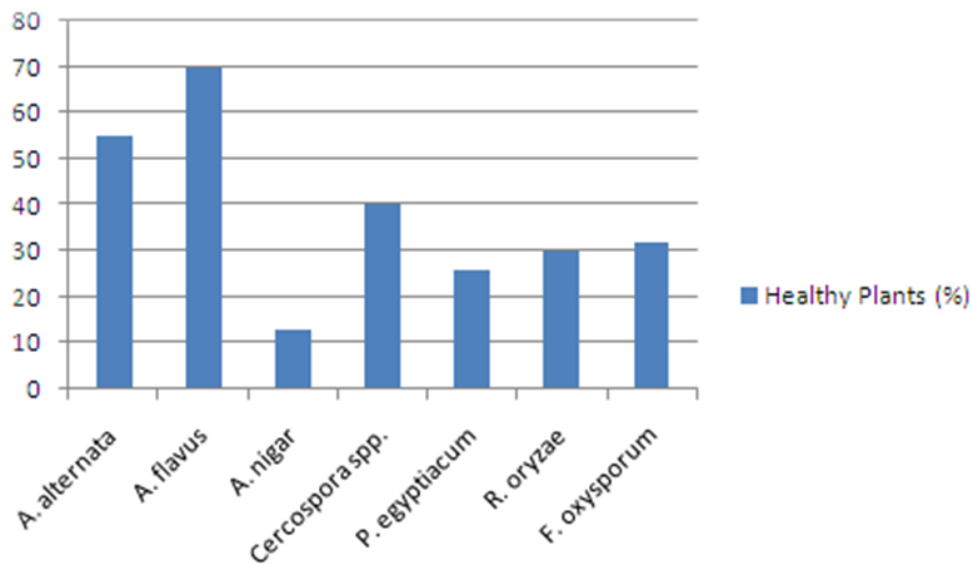

\section{Conclusion}

The results of this study may provide valuable information that the laboratory treatments given to seeds before sowing are helpful to the increase the seed vigor and the health of seedlings. Abnormality rate of seedlings depends on the type of pathogens with which they are infected. There is also need for the management programs to control seed borne pathogens and reduce their impact on sesame production in Pakistan. Because it has also been noted that the fungal pathogens of sesame seeds are responsible for the production of seeds of poor quality, including seed contaminated with mycotoxins.

\section{References}

[1]. Afzal, R., S. M. Mughal, M. Munir, K. Sultana, R. Qureshi, M. Arshad and M. K. Laghari. 2010. Mycoflora associated with seeds of different sunflower cultivars and its management. Pak. J. Bot., 42: 435-445.

[2]. Altaf, N., S. A. Khan, M. Ahmed, R. Asghar, R. A. Ahmed, S. Shaheen, M. Zafar and M. Saqib. 2004. Seed borne Mycoflora of Sesame (Sesamum indicum L.) and their effect on germination and seedling. Pak. J. Biol. Sci., 7: 243-245.

[3]. Anonymous. 2008. World Sesame situation, American Sesame Growers Association. http://www.sesamegrowers.org/worldstatusofsesame.htm (15/01/08).

[4]. Christensen, C. M. and H. H. Kaufman. 1969. Grain storage. The role of fungi in quality losses. Univ. Minnesota, Press Minneapolis.

[5]. Daniel, E. 2008. Investigation of the Genetic Variability among Land Races of Sesame from Ethiopia, MA Thesis, University of Hohenhein, Stuttgart, Germany.

[6]. FAO. 2004. Agricultural data. In "Agricultural Statistics databases". Organization of the United Nations, Rome, Italy. http://faostat.fao.org

[7]. Khidir, M. O. 1997. Oilseed Crops in the Sudan (in Arabic). Khartoum University Press, Khartoum, Sudan.

[8]. Mahdy, A. M. M., N. A. Eisa, A. A. El-Wakil, F. M. Abdel-Latif, and D. A. El-Wakil. 2007. Effect of some resistance inducing agents and antagonistic fungi on the linear growth of Macrophomina phaseolina and Fusarium oxyosporum the causal agents of charcoal rot and wilt of Sesame in vitro. Annals of Agri. Sci., Moshtohor, 45:561-567

[9]. Nayyar, B. G., A. Akram, M. Arshad, S. M. Mughal, S. Akhund and S. Mushtaq (2013). Mycoflora Detected from Seeds of Sesamum indicum L. in Sialkot, Pakistan. IOSR Journal of Pharmacy and Biological Science. 7(3): 99-104

[10]. Roy, N., S. M. Abdullah and M. S. Jahan. 2009. Yield performance of sesame (Sesamum indicum L.) varieties at varying levels of row spacing. Research Journal of Agriculture and Biological Sciences, 5(5): 823-827. 